\title{
EVALUASI KINERJA PERBAIKAN TANAH LUNAK DENGAN MENGGUNAKAN PRELOADING DAN PREFABRICATED VERTICAL DRAIN (PVD)
}

\author{
Zahra Febrina Lilabsari ${ }^{1}$, As'ad Munawir ${ }^{2}$, Yulvi Zaika ${ }^{2}$, Wahyu P. Kuswanda ${ }^{3}$ \\ ${ }^{1}$ Mahasiswa / Program Studi Sarjana Teknik Sipil Fakultas Teknik / Universitas Brawijaya \\ ${ }^{2}$ Dosen / Jurusan Teknik Sipil Fakultas Teknik / Universitas Brawijaya \\ ${ }^{3}$ Direktur / PT. Teknindo Geosistem Unggul \\ Korespondensi : zahrafebrina1996@gmail.com
}

\begin{abstract}
The settlement of soil consolidation is geotechnical problem which is often found in soft soil accumulation. It is therefore, Preloading and Prefabricated Vertical Drain techniques are used to accelerate consolidational settlement. The problem which often appeared in using Preloading and Prefabricated Vertical Drain (PVD) is the failure of design. It causes the consolidationtime cannot run in accordance with the planning. In order to have soil improvemet method which has high effectiveness it is necessary to evaluate the use of geotechnical instruments. In this study, the evaluation covers 3 (three) geotechnical instruments, where Settlement Plate is used to evaluate theoretical settlement, to calculate final settlement prediction with Asaoka observation method and consolidation degree in the field. Consolidation degree also can be evaluated using Pneumatic Piezometer instrument. The inclinometer is used to evaluated the stability of embankment. The failure of design in using Preloading and Prefabricated Vertical Drain (PVD) can be accured because of the mistake of planner in determaining soil design parameters, therefore this study also discusses soil design parameters in actual condition using back analysis method. The results obtained in this study are comparison of actual and theoretical settlement on average of 0.862. To predict final settlement it can be obtained the value 2191,08 mm with the rest of settlement which will be accured about $100-450 \mathrm{~mm}$. In this study the actual consolidation degree from Piezometer reading is $85,36 \%$ and Settlement Plate reading is $88,42 \%$ with the difference of 3,06\%. From Inclinometer reading lateral shift which is accured below the soil there is no land slide so that the embankment which is used remains safe The result of back analysis method is Ch value where the new Ch value is 1,914Cv.
\end{abstract}

Keywords : Consolidation, Preloading, Prefabricated Vertical Drain, Geotechnical Instruments, Asaoka

\section{PENDAHULUAN}

Berdasarkan analisa penyelidikan tanah, kondisi tanah di Gedebage, Bandung, merupakan tanah lunak. Tanah lunak merupakan tanah yang memiliki nilai kemampumampatan yang relatif tinggi. Kemampumampatan yang tinggi tersebut dapat menyebabkan tanah mengalami penurunan akibat keluarnya air pori yang terkandung dalam tanah jika tanah diberikan beban struktur (konsolidasi tanah). Untuk itu perlu diadakannya usaha perbaikan pada tanah lunak tersebut. Terdapat beberapa metode perbaikan tanah diantaranya yaitu perbaikan tanah secara mekanis, dengan cara perkuatan, dengan menggunakan material geosintetik dan bahan pencampur (additive) [1].

Perbaikan tanah yang umum digunakan ialah Preloading yang dikombinasikan Prefabricated Vertical Drain (PVD). PVD merupakan pita vertikal sintetis yang ditanamkan ke dalam tanah lunak dimana pita tersebut berfungsi untuk mengalirkan air dan udara di dalam tanah menuju ke permukaan. Pada perbaikan tanah dengan menggunakan metode preloading dengan PVD, input berupa tanah yang mudah mampat (compressible soil) dan kemudian dilakukan percepatan pemampatan (consolidation acceleration). Hasil dari akhir / 
output berupa tanah yang relative selesai pemampatannya (non-compressible soil) [2].

Pada penggunaan Preloading dan PVD di lapangan, akan muncul beberapa permasalahan salah satunya adalah pada monitoring proses konsolidasi dan kegagalan desain yang menyebabkan waktu konsolidasi tidak berjalan sesuai rencana. Kegagalan desain ini dapat terjadi karena kesalahan perencana dalam menentukan parameter-parameter desain yang sesuai dengan keadaan aktualnya.

Agar perbaikan tanah pada kawasan Kota Summarecon Bandung memiliki efektivitas yang tinggi, perlu diadakannya evaluasi terhadap kinerja perbaikan tanah yang ditinjau oleh instrument geoteknik serta parameter desain yang digunakan.

\section{TINJAUAN PUSTAKA}

Penambahan beban diatas suatu permukaan tanah dapat menyebabkan lapisan tanah mengalami pemampatan. Pemampatan tersebut dapat terjadi karena adanya deformasi partikel tanah, relokasi partikel, keluarnya air pori, dan sebab-sebab lainnya [3].

\subsection{Preloading}

Preloading atau metode pembebanan awal merupakan suatu metode perbaikan tanah yang berupa penempatan timbunan pada lokasi perbaikan tanah dengan berat sekurang kurangnya sama dengan berat sekurangkurangnya sama dengan berat struktur yang akan digunakan dan akan dibuang jika konsolidasi telah tercapai (Pedoman Konstruksi dan Bangunan, 2004). Pada penggunaan Preloading menggunakan timbunan, beban timbunan direncanakan dengan ketinggian tertentu agar penurunan konsolidasi dapat tercapai. Stamatopoulos dalam Yunias [4] mengatakan tinggi timbunan umumnya berkisar antara $3-8$ meter dengan penurunan yang akan terjadi umumnya $0,3-2$ meter.

\subsection{Prefabricated Vertical Drain (PVD)}

Prefabricated Vertical Drain atau PVD ialah produk berbentuk pita (potongan melintang segiempat) yang terdiri atas material penyering geotekstil yang membungkus inti plastik. Material dibentuk dari inti plastik yang berguna untuk mengalirkan air yang terjebak pada saringan geotektil. Ukuran PVD adalah $10 \mathrm{~cm}$ lebar dengan ketebalan antara 3-4 cm.

Penggunaan PVD lebih umum digunakan dalam perbaikan tanah [5] [6] karena memiliki banyak keuntungan, diantaranya:

1. Gangguan pada tanah yang diakibatkan saat pemasangan lebih kecil

2. Waktu yang dibutuhkan saat control kualitas lebih cepat

3. Kualitas PVD cenderung seragam

4. Tahan terhadap deformasi besar tanpa terlalu banyak kehilangan fungsi drainase

5. Kontaminasi butiran halus pada tanah asli jauh lebih kecil

6. Pemasangan lebih cepat dan ekonomis.

\subsection{Settlement Plate}

Settlement plate merupakan instrument geoteknik yang berfungsi untuk memonitoring proses penurunan tanah. Settlement plate terdiri dari beberapa bagian yaitu plat besi berukuran 50 x 50 x $1 \mathrm{~cm}$, pipa besi, pipa paralon dan waterpass dengan pemasangan alat berada di tengah timbunan atau area dimana akan terjadi penurunan maksimum.

Settlement plate memonitoring nilai penurunan tanah yang timbul akibat Preloading, sehingga proses penurunan tanah yang terjadi aman dari sliding atau longsor. Settlement plate dapat dinyatakan tidak aman apabila grafik penurunan yang terbaca terjadi fluktuasi yang sangat ekstrem.

Dari bacaan Settlement Plate dapat pula diketahui nilai derajat konsolidasi dengan membandingkan besar penurunan aktual pada waktu tertentu terhadap penurunan total atau sesuai dengan :

$$
\begin{aligned}
& \boldsymbol{U}_{\boldsymbol{v}-\boldsymbol{s p}}=\frac{\boldsymbol{s}_{\boldsymbol{t}}}{\boldsymbol{S}_{\boldsymbol{c}}} \\
& \mathrm{S}_{\mathrm{t}}=\text { penurunan konsolidasi dari bacaan } \\
& \quad \text { settlement plate pada waktu } \mathrm{t} \\
& \mathrm{S}_{\mathrm{c}}=\text { penurunan total }
\end{aligned}
$$

\subsection{Pneumatic Piezometer}

Piezometer merupakan alat yang berfungsi untuk mengetahui perubahan air pori pada tanah dasar. Piezometer terbagi menjadi beberapa bagian yaitu casing, tip Piezomete, filter sand, bentonite tablet dan grouting.

Dari nilai tegangan air pori yang didapat dari bacaan Piezometer maka dapat ditentukan 
nilai derajat konsolidasi dengan persamaan berikut :

$$
\begin{aligned}
& \boldsymbol{U}_{\boldsymbol{v}-\boldsymbol{s p}}=\frac{\mathbf{1}-\Delta \boldsymbol{U}_{\boldsymbol{e}}}{\boldsymbol{U}_{\boldsymbol{e}}} \\
& \text { Dimana: } \\
& \mathrm{U}_{\mathrm{e}}=\text { tegangan air pori awal }(\mathrm{t}=0) \\
& \Delta \mathrm{U}_{\mathrm{e}}=\text { tegangan air pori bacaan Piezometer }
\end{aligned}
$$

\subsection{Inclinometer}

Inclinometer merupakan satu unit instrument geoteknik yang digunakan untuk memantau pergerakan lateral tanah yang terjadi dibawa permukaan. Alat ini berfungsi untuk mengetahui kemungkinan terjadinya sliding atau keruntuhan pada timbunan.

Kestabilan timbunan dapat dapat ditinjau dengan 2 persyaratan, yaitu:

1. Syarat 1

$$
\begin{aligned}
& \mathrm{Y}_{\mathrm{Z}}<\mathrm{Y}_{\mathrm{Z} \max } \text { dimana } \\
& \boldsymbol{Y}_{\boldsymbol{Z}}=\frac{\boldsymbol{Y}_{\boldsymbol{Z} \text { max }}}{\boldsymbol{F S}} \text { dan } \boldsymbol{Y}_{\boldsymbol{z} \text { max }}=\mathbf{0}, \mathbf{1 6} \boldsymbol{S}_{\boldsymbol{c}} \\
& \mathrm{Y}_{\mathrm{Z}}=\text { pergeseran tanah yang terjadi saat ini } \\
& \mathrm{Y}_{\mathrm{z}} \text { max }=\text { pergeseran tanah maksimum } \\
& \quad \text { yang diizinkan } \\
& \mathrm{S}_{\mathrm{c}}=\text { penurunan tanah } \\
& \mathrm{FS}=\text { faktor keamanan }(\mathrm{FS}=1,3)
\end{aligned}
$$

2. Syarat 2

$$
\begin{aligned}
& \Delta_{\mathrm{n}}<\ldots<\Delta_{3}<\Delta_{2}<\Delta_{1} \\
& \Delta_{\mathrm{n}}=\text { selisih bacaan Inclinometer }
\end{aligned}
$$

\subsection{Metode Asaoka}

Metode Asaoka [7] merupakan salah satu metode yang digunakan untuk memprediksi nilai penurunan akhir (final settlement). Metode ini merupakan alat bantu untuk memprediksi final settlement dengan menggunakan curve fitting.

Dari hasil penurunan akhir dapat diketahui nilai koefisien horizontal yang sesuai dengan keadaan aktual di lapangan, dihitung dengan persamaan sebagai berikut :

$$
\begin{aligned}
& \frac{\pi^{2} C_{v}}{\mathbf{8} H^{2}}+\frac{8 C_{h}}{D^{2} F_{n}}=-\frac{\ln \beta}{\delta_{t}} \\
& \beta=\text { kemiringan garis pada grafik Asaoka } \\
& \delta_{\mathrm{n}}=\text { interval waktu pada grafik Asaoka }
\end{aligned}
$$

\section{METODOLOGI PENELITIAN}

Metode penelitian yang digunakan yaitu dengan mengumpulkan data sekunder yang nantinya akan diolah sesuai dengan kebutuhan analisis

\subsection{Lokasi Kajian}

Kajian dilakukan pada proyek pembangunan Summarecon Bandung, Jawa Barat. Area proyek yang ditinjau adalah area cluster Amanda dan Btari dimana area tersebut akan dibangun sebuah kawasan perumahan 2 lantai.

\subsection{Tahap dan Prosedur Analisis}

Tahap dan prosedur analisis dilakukan dengan sistematis. Tahapan dan prosedur analisis yang akan dilaksanakan adalah sebagai berikut:

1. Studi literatur

2. Pengumpulan dan pemilihan data sekunder

3. Analisis data

4. Pembahasan

\subsection{Teknik Pengumpulan Data}

Data yang digunakan merupakan data sekunder yang merupakan studi pustaka dan literatur ilmiah yang berkaitan dengan analisis ini.

Dalam analisis dihitung besar penurunan konsolidasi secara teoritis dengan menggunakan pendekatan Terzaghi, memprediksi penurunan konsolidasi akhir dengan metode Asaoka serta mencari nilai parameter-parameter tanah. Besarnya prediksi penurunan konsolidasi dari teori Asaoka serta besarnya penurunan konsolidasi dari bacaan Settlement Plate di-plot pada suatu grafik lalu dibandingkan antara keduanya

Derajat konsolidasi dihitung dari hasil perhitungan berdasarkan data tanah yang ada, dari bacaan Settlement Plate, serta bacaan Pneumatic Piezometer. Dari keseluruhan hasil pengolahan data tersebut dapat dicari besarnya nilai koefisien konsolidasi tanah arah horizontal $\left(\mathrm{C}_{\mathrm{h}}\right)$ dan parameter lainnya yang sesuai dengan tanah di lapangan. Dengan didapatkannya nilainilai parameter yang sesuai maka dapat diketahui desain pemasangan preloading dan Prefabricated Vertical Drain (PVD) yang baik untuk memaksimalkan kinerja metode perbaikan tanah tersebut

Syarat kestabilan pada tanah timbunan ditinjau berdasarkan data Inclinometer. Dari hasil 
pengolahan data dapat diketahui longsor atau tidaknya timbunan yang digunakan.

\section{PEMBAHASAN}

Data yang diperoleh dipilih sedimikian rupa sehingga data siap digunakan. Data diolah untuk mendapatkan hasil akhir penurunan tanah, derajat konsolidasi, kestabilan timbunan serta parameter-parameter tanah yang sesuai dengan keadaan aktualnya.

\subsection{Perhitungan Penurunan Konsolidasi Teoritis}

Penurunan konsolidasi awal dihitung berdasarkan teori one dimensional settlement dimana tanah dianggap over consolidated. Pada perhitungan penurunan digunakan data tanah dasar yang telah dipilih dan disesuaikan untuk hasil penurunan yang wajar. Penurunan dapat dihitung dengan rumus:

$$
S_{c}=\frac{C s . h}{1+e_{0}} x \log \left(1+\frac{\Delta \sigma}{\sigma_{0}}\right)
$$

Dari rumus tersebut didapat nilai penurunan terhadap masing-masing titik settlement plate yang digunakan seperti pada Tabel 1.

Tabel 1. Hasil penurunan akhir secara teoritis

\begin{tabular}{|c|c|c|c|c|c|}
\hline \multirow[b]{2}{*}{$\begin{array}{c}\text { Setulement } \\
\text { Plate }\end{array}$} & \multirow{2}{*}{$\begin{array}{c}\text { Penurunan } \\
\text { hari ke } 382 \\
\text { bacaan SP } \\
\text { (mm) }\end{array}$} & \multirow{2}{*}{$\begin{array}{c}\text { Penuruman } \\
\text { Alkhir } \\
\text { (mm) }\end{array}$} & \multirow[b]{2}{*}{$\begin{array}{c}\text { Derajat } \\
\text { Konsolidasi } \\
\text { (\%) }\end{array}$} & \multicolumn{2}{|c|}{ Residual } \\
\hline & & & & $(\%)$ & $\mathrm{mm}$ \\
\hline SP-16 & 1299 & $1:$ & 81.9225 & 18.0775 & 286.6448 \\
\hline SP. 26 & 2363 & & 87.7682 & 122318 & 3293204 \\
\hline SP-27? & 2196 & 2477,6194 & 88.6335 & 113665 & 281.6194 \\
\hline SP-28 & 1434 & 16548364 & 86.6551 & 13.3449 & 220.8364 \\
\hline$S P-31$ & 2324 & 2738.2262 & 848725 & 15.1275 & 4142262 \\
\hline Rata-rata & 1923 & 2229.7294 & 85.9703 & 14.0297 & 306.5294 \\
\hline
\end{tabular}

Untuk mengetahui penurunan teoritis yang terjadi pada hari ke 382, perlu dihitung terlebih dahulu nilai derajat konsolidasi. Pada saat penimbunan, PVD telah dipasang sehingga perhitungan derajat konsolidasi sudah menggunakan persamaan-persamaan yang berhubungan dengan vertical drains.

Dari nilai derajat konsolidasi dan penurunan teoritis total dapat diketahui nilai penurunan teoritis pada hari 382, sehingga penurunan aktual dan perhitungan teoritis dapat dibandingkan. Hasil dari nilai-nilai tersebut ditampilkan pada Tabel $\mathbf{2}$ dengan contoh grafik yang ditampilkan pada Gambar 1.

\subsection{Prediksi Penurunan Akhir Metode Asaoka}

Prediksi besarnya penurunan akhir metode Asaoka dihitung berdasarkan data bacaan Settlement Plate. Sebagai contoh digunakan data SP-16 yang dimulai pada hari ke-262 hingga hari ke-307 dengan interval $\Delta \mathrm{t}$ adalah 3 hari sesuai dengan Tabel 3.

Selanjutnya dilakukan prediksi penurunan akhir metode Asaoka dengan mencari nilai regresinya sehingga dapat diketahui prediksi penurunan akhir yang dapat tercapai seperti yang ditunjukka pada Gambar 2. Berdasarkan hasil regresi, penurunan akhir yang terjadi pada SP-16 adalah sebesar 1457,69. Dilakukan pula terhadap data SP yang lainnya sehingga didapat estimasi penurunan akhir seperti terlihat pada Tabel 4.

Tabel 2. Perbandingan penurunan hari ke-382

\begin{tabular}{|c|c|c|c|}
\hline $\begin{array}{c}\text { Sirtitement } \\
\text { Plate }\end{array}$ & $\begin{array}{l}\text { Penumanan } \\
\text { s.d. hati ke } \\
382 \text { (man) }\end{array}$ & $\begin{array}{c}\text { Petuaruaan } \\
\text { Teotitis lingga } \\
\text { hari Ler-382 (m) }\end{array}$ & $\begin{array}{l}\text { Peibandinean } \\
\text { Searael dengan } \\
\text { Scienom }\end{array}$ \\
\hline SP-16 & 1299 & 1585.6019 & 0.81925 \\
\hline SP.26 & 2363 & 26922475 & 0.87771 \\
\hline SP.27 & 2196 & 2477.5523 & 0.88636 \\
\hline SP.28 & 1434 & 1654.7915 & 0.86657 \\
\hline SP-31 & 2324 & 2738.1520 & 0.84875 \\
\hline Rata-rata & 1923 & 2229.6690 & 0.86255 \\
\hline
\end{tabular}

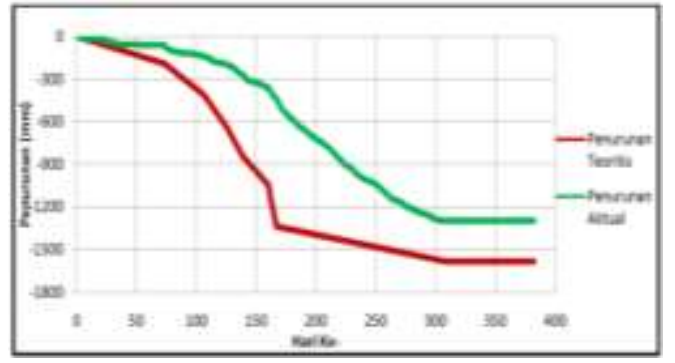

Gambar 1. Grafik perbandingan penurunan SP16

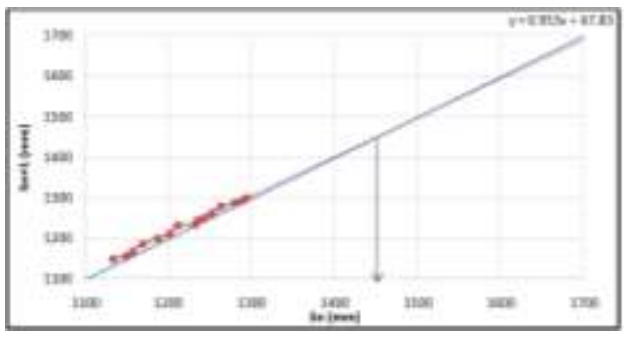

Gambar 2. Grafik Asaoka SP-16 


\subsection{Derajat Konsolidasi Bacaan Settlement Plate}

Nilai derajat konsolidasi dari bacaan SP dilakukan dengan membandingkan besar penurunan aktual pada waktu tertentu dengan nilai penurunan akhir yang diperoleh dari metode Asaoka sesuai dengan persamaan 1. Nilai derajat konsolidasi berdasarkan masing-masing data Settlement Plate ditampilkan pada Tabel 5.

Tabel 3. Penurunan hari ke-n SP-16

\begin{tabular}{ccccc}
\hline Hari Ke-n & $\begin{array}{c}\text { Interval } \\
\text { Ke-n }\end{array}$ & Sn & Sumbu X & Sumbu Y \\
\hline 262 & 1 & 1133 & 1133 & 1150 \\
265 & 2 & 1150 & 1150 & 1157 \\
268 & 3 & 1157 & 1157 & 1169 \\
271 & 4 & 1169 & 1169 & 1187 \\
274 & 5 & 1187 & 1187 & 1201 \\
277 & 6 & 1201 & 1201 & 1211 \\
280 & 7 & 1211 & 1211 & 1233 \\
283 & 8 & 1233 & 1233 & 1235 \\
286 & 9 & 1235 & 1235 & 1244 \\
289 & 10 & 1244 & 1244 & 1252 \\
292 & 11 & 1252 & 1252 & 1263 \\
295 & 12 & 1263 & 1263 & 1280 \\
298 & 13 & 1280 & 1280 & 1289 \\
301 & 14 & 1289 & 1289 & 1294 \\
304 & 15 & 1294 & 1294 & 1299 \\
307 & 16 & 1299 & & \\
\hline
\end{tabular}

Tabel 4. Hasil penurunan akhir metode Asaoka

\begin{tabular}{ccc}
\hline $\begin{array}{c}\text { Settlement } \\
\text { Plate }\end{array}$ & $\begin{array}{c}\text { Penurunan s.d. } \\
\text { hari ke } 382(\mathbf{m m})\end{array}$ & $\begin{array}{c}\text { Penurunan } \\
\text { Akhir }(\mathbf{m m})\end{array}$ \\
\hline SP-16 & 1299 & 1457.6918 \\
SP-26 & 2363 & 2694.3003 \\
SP-27 & 2196 & 2495.1829 \\
SP-28 & 1434 & 1533.8951 \\
SP-31 & 2324 & 2774.3513 \\
\hline Rata-rata & 1923 & $\mathbf{2 1 9 1 . 0 8 4 3}$ \\
\hline
\end{tabular}

Tabel 5. Penurunan hari ke-n SP-16

\begin{tabular}{|c|c|c|c|c|c|}
\hline \multirow{2}{*}{$\begin{array}{c}\text { Setrlennent } \\
\text { Plate }\end{array}$} & \multirow{2}{*}{$\begin{array}{l}\text { Peseuruaas } \\
\text { sd. hari te } \\
\text { 382 (aum) }\end{array}$} & \multirow{2}{*}{$\begin{array}{l}\text { Pesuranas } \\
\text { Akhir } \\
\text { (aum) }\end{array}$} & \multirow{2}{*}{$\begin{array}{c}\text { Derajat } \\
\text { Kensetidasi } \\
(\% / n)\end{array}$} & \multicolumn{2}{|c|}{ Resideal } \\
\hline & & & & $(76)$ & $\operatorname{man}$ \\
\hline sp. 16 & 1290 & 1457.69 & 8.11 & $10 \times 5$ & $15 \times 60$ \\
\hline $5 P=26$ & 236.7 & 260430 & 67,70 & 12.30 & 331.3 \\
\hline Sp.27 & 2196 & 2495.18 & kx.01 & 1199 & $209.1 \mathrm{x}$ \\
\hline SP.28 & 1434 & 1533.89 & 93.49 & 6.51 & 99.89 \\
\hline SP.21 & 2324 & $277+35$ & $x: 77$ & 1627 & 4503 \\
\hline Rata-rata & 1923 & 2191.08 & $8 x+1$ & 11.58 & $267.8 x$ \\
\hline
\end{tabular}

\subsection{Derajat Konsolidasi Bacaan Piezometer}

Derajat konsolidasi dapat ditentukan melalui bacaan Piezometer dimana data tegangan air pori yang terbaca adalah $209,5 \mathrm{kPa}, 163,5$ $\mathrm{kPa}$, dan $114 \mathrm{kPa}$. Sesuai pada Gambar 3, derajat konsolidasi dapat dihitung dengan menggunakan persamaan 2 dimana dari hasil perhitungan diketahui nilai derajat konsolidasi berdasarkan bacaan Piezometer sebesar 85,36\%.

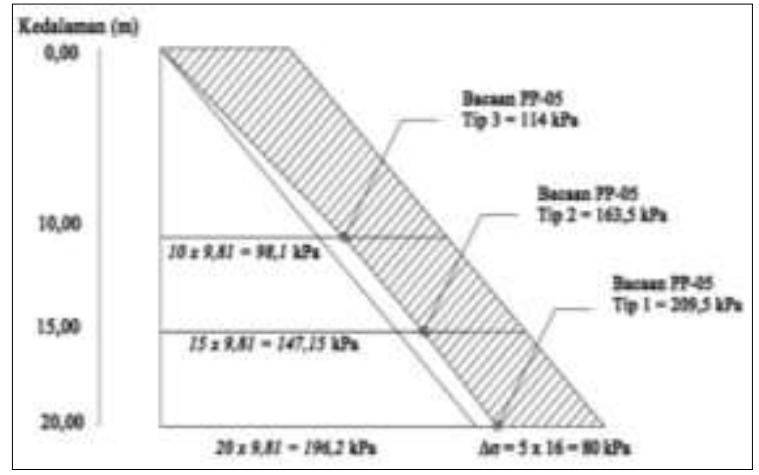

Gambar 3. Kelebihan tegangan air pori

\subsection{Kestabilan Tanah pada Timbunan}

Kestabilan tanah timbunan ditentukan melalui data bacaan Inclinometer. Dari bacaan Inclinometer didapat nilai puncak pergeseran tanah lateral terjadi pada kedalaman 12,5 m untuk arah A dan 10,5 untuk arah B. Kestabilan timbunan ditinjau sesuai syarat.

Untuk syarat kestabilan $1, \mathrm{Y}_{\mathrm{z}}<\mathrm{Y}_{\mathrm{z} \max }$, diketahui nilai $Y_{z}=219,5 \mathrm{~mm}$ dan $Y_{z \max }=285,3$ mm. Sesuai dengan persyaratan, maka timbunan dinyatakan aman dari kelongsoran

Syarat kestabilan 2 didapat dari masingmasing selisih bacaan Inclinometer. Sesuai dengan $\Delta_{\mathrm{n}}<\ldots<\Delta_{3}<\Delta_{2}<\Delta_{1}$, tanah timbunan yang digunakan aman baik arah $\mathrm{A}$ maupun arah B.

\subsection{Analisa Balik Parameter Tanah}

Perhitungan analisa balik parameter tanah meliputi koefisien konsolidasi tanah arah horizontal $\left(\mathrm{C}_{\mathrm{h}}\right)$, koefisien kompresibilitas volume $\left(\mathrm{m}_{\mathrm{v}}\right)$, permeabilitas tanah arah vertikal $\left(\mathrm{k}_{\mathrm{v}}\right)$ dan indeks pemampatan $\left(\mathrm{C}_{\mathrm{c}}\right)$.

Koefisien konsolidasi arah horizontal $\left(\mathrm{C}_{\mathrm{h}}\right)$ dapat diketahui dari nilai $\beta$ pada persamaan grafik Asaoka. Nilai koefisien kompresibilitas volume $\left(\mathrm{m}_{\mathrm{v}}\right)$ dihitung apabila telah diketahui 
nilai penurunah akhir, kedalaman PVD serta penambahan tegangan pada timbunan. Permeabilitas tanah arah vertikal $\left(\mathrm{k}_{\mathrm{v}}\right)$ didapat dari hubungannya dengan $m_{v} . C_{c}$ atau indeks pemampatan didapat dari perhitungan ulang penurunan konsolidasi. Parameter tanah ditampilkan pada Tabel 6.

Tabel 6. Parameter tanah hasil analisa balik

\begin{tabular}{|c|c|c|c|c|c|}
\hline $\begin{array}{c}\text { Serthoment } \\
\text { Mlate }\end{array}$ & $\begin{array}{c}\text { Ch } \\
\left(\mathbf{m}^{2} / \mathrm{har}\right)\end{array}$ & $\mathrm{ChCV}$ & $\underset{\left(a^{2} / k V\right)}{a k}$ & $\begin{array}{c}\text { ks } \\
\text { (m)hari) }\end{array}$ & $C_{k}$ \\
\hline $8 P \cdot 16$ & 000841 & 1.1630 & $0.000 \times 26$ & $5 \times 55101.45$ & 101954 \\
\hline sP. -26 & 001541 & 2.1 .408 & 6. oxionsy & 6. 39790E-45 & 1.34626 \\
\hline SP-27 & 001903 & 2.7570 & 0.000037 & $6.64796 \mathrm{E}-95$ & 13444 \\
\hline $810.2 \mathrm{~K}$ & 0.00052 & 13171 & 0.000016 & $6.35714 \mathrm{t}-95$ & 111183 \\
\hline SP.31 & 001593 & 22035 & 0000024 & $6924781-05$ & 139373 \\
\hline Rata-Rata & 0.01384 & 1.91426 & อ. & 0.0000064 & 1.24524 \\
\hline
\end{tabular}

\subsection{Prediksi Waktu Tunggu Konsolidasi Mencapai 90\%}

Berdasarkan hasil perhitungan analisa balik, diperoleh nilai koefisien konsolidasi arah horizontal $\left(\mathrm{C}_{\mathrm{h}}\right)$ baru yang digunakan untuk menghitung prediksi waktu tunggu konsolidasi mencapai $90 \%$. Hasil prediksi waktu tunggu ditampilkan pada Tabel 7.

Tabel 7. Prediksi waktu tercapai konsolidasi $90 \%$

\begin{tabular}{|c|c|c|c|c|}
\hline \multirow{2}{*}{$\begin{array}{c}\text { Sintlenument } \\
\text { Plate }\end{array}$} & \multirow{2}{*}{$\begin{array}{c}\text { Ch } \\
\text { (mathi }\end{array}$} & \multirow{2}{*}{$\begin{array}{c}\text { Sea Hari } \\
\text { Meanju } \\
\text { Kensolidad } \\
\text { 90\% }\end{array}$} & \multicolumn{2}{|c|}{$\begin{array}{l}\text { Preiliksi Wabtu Tunegu } \\
\text { Kensolidasi Mencapai } 90 \% \text {, }\end{array}$} \\
\hline & & & Hari & Tangesal \\
\hline SP-16 & 0.00841 & $6 \mathrm{Han}$ & Achned & 24 Agantes 2017 \\
\hline SP.26 & 0.01541 & 21 ftan & Achived & 8 Septeraber 2017 \\
\hline SP-27 & 0.01993 & $2+\mathrm{Hari}$ & Achived & 11 September 2917 \\
\hline SP-28: & 0.00952 & - & Achived & 30 Juni 2017 \\
\hline SP-31 & 0.01593 & 43 Hani & Achived & 30 Sequanba 2017 \\
\hline
\end{tabular}

\section{KESIMPULAN}

Dari penelitian evaluasi kinerja perbaikan tanah menggunakan instrument geoteknik dapat disimpulkan :

1. Perbandingan besarnya penurunan aktual dan teoritis dapat diketahui bahwa penurunan secara aktual lebih kecil dari pada penurunan teoritis dengan nilai perbandingan tiap SP yang ditinjau berturut-turut adalah sebesar $0.819,0.878,0.886,0.867$ dan 0.849 dengan perbandingan rata-rata sebesar 0.862 .

2. Dari metode Asaoka diketahui besar prediksi penurunan akhir pada SP yang ditinjau adalah sebesar $1457.69 \mathrm{~mm}, 2694.3 \mathrm{~mm}, 2495.18$ $\mathrm{mm}, 1533.89 \mathrm{~mm}$ dan $2774.35 \mathrm{~m}$. Penurunan masih akan terus berjalan sekitar $6-43$ hari dengan penurunan yang akan terjadi berkisar $100-450 \mathrm{~mm}$.

3. Pada akhir pembacaan Piezometer derajat konsolidasi yang telah tercapai adalah sebesar $85.359 \%$ dan derajat konsolidasi rata-rata dari bacaan Settlement Plate sebesar 88,416\%

4. Dari analisa balik didapatkan parameterparameter tanah baru sebagai berikut:
a. $\mathrm{C}_{\mathrm{h}}=.01384$
b. $\mathrm{C}_{\mathrm{h}} / \mathrm{C}_{\mathrm{v}}=1.914$
c. $\mathrm{m}_{\mathrm{v}}=0.000898 \mathrm{~m}^{2} / \mathrm{kN}$
d. $\mathrm{k}_{\mathrm{v}}=0.000064 \mathrm{~m} / \mathrm{hari}$
e. $\mathrm{C}_{\mathrm{c}}=1,24324$

\section{DAFTAR PUSTAKA}

[1] Jafri, Muhammad. Metoda Perbaikan Tanah Lunak Pada Ruas Jalan Sekincau-Suoh di Kabupaten Lampung Barat, Rekayasa, Jurnal Sipil dan Perencanaan, Vol.13 No.2, 2009.

[2] Kuswanda, Wahyu P. Perbaikan Tanah Lempung Lunak Metoda Preloading Pada Pembangunan Infrastruktur Transportasi di Pulau Kalimantan. Prosiding Seminar Nasional Geoteknik.2016

[3] Hardiyatmo, Hary C., Mekanika Tanah I, Yogyakarta: UGM Press.2002

[4] Yunias, Lishia. 2010. Analisa Balik Parameter Desain Preloading Dengan Vertical Drains Studi Kasus Perbaikan Tanah PT. Pupuk Kaltim Bontang. Skripsi. Jakarta. Universitas Bina Nusantara

[5] Winner, Dofran; Noor Endah, Putu Tantri Kumalasari. Perbaikan Tanah Dasar Menggunakan Pre-Fabricated Vertical Drain Dengan Variasi Kedalaman dan Perkuatan Lereng Dengan Turap (Studi Kasus : Lapangan Peumpukan Peti Kemas, Pelabuhan Trisakti, Banjarmasin, Kalimantan Selatan). Jurnal Teknik ITS, Vol.6, No.1.2017

[6] Ohoimas, M., Y.; Hamdhan, I.,N. Analisis Konsolidasi dengan Menggunakan Metode Preloading dan Vertical Drain pada Areal Reklamasi Proyek Pengembangan Pelabuhan Belawan Tahap II. Reka Racana, Vol.1, No.1, 2015.

[7] Asaoka, A. Observational Procedure of Settlement Prediction. Soils and Foundation, No.4.1978. 